STUDI

FRANCESI

\section{Studi Francesi}

Rivista quadrimestrale fondata da Franco Simone

159 (LIII | III) | 2009

Varia

\title{
Prosper Mérimée au temps de Napoléon III, Actes du colloque organisé au musée national du château de Compiègne, 18 octobre 2003, sous la direction de F. Maison
}

\section{Michel Arrous}

\section{OpenEdition}

\section{Journals}

Édition électronique

URL : http://journals.openedition.org/studifrancesi/7641

DOI : 10.4000/studifrancesi.7641

ISSN : 2421-5856

Éditeur

Rosenberg \& Sellier

Édition imprimée

Date de publication : 1 décembre 2009

Pagination : 650

ISSN : 0039-2944

Référence électronique

Michel Arrous, "Prosper Mérimée au temps de Napoléon III, Actes du colloque organisé au musée national du château de Compiègne, 18 octobre 2003, sous la direction de F. Maison », Studi Francesi [En ligne], 159 (LIII | III) | 2009, mis en ligne le 30 novembre 2015, consulté le 09 janvier 2021. URL : http://journals.openedition.org/studifrancesi/7641 ; DOI : https://doi.org/10.4000/studifrancesi.7641

Ce document a été généré automatiquement le 9 janvier 2021.

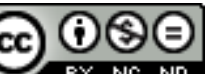

Studi Francesi è distribuita con Licenza Creative Commons Attribuzione - Non commerciale - Non opere derivate 4.0 Internazionale. 
Prosper Mérimée au temps de Napoléon III, Actes du colloque organisé au musée national du château de Compiègne, 18 octobre 2003, sous la direction de F. Maison

\author{
Michel Arrous
}

\title{
RÉFÉRENCE
}

AA. VV., Prosper Mérimée au temps de Napoléon III, Actes du colloque organisé au musée national du château de Compiègne, 18 octobre 2003, sous la direction de F. MAISON, Editions de la Réunion des Musées Nationaux, 2008, pp. 101.

1 Parmi les manifestations de l'automne 2003 célébrant le bicentenaire de la naissance de Mérimée, il y eut un colloque modeste mais fort dense consacré aux vingt dernières années de l'écrivain, historien et archéologue. Françoise MAISON, qui en fut l'organisatrice, parla de Prosper Mérimée à la Cour de Napoléon III et d'Eugénie (pp. 11-36). À partir de la Correspondance générale, de la presse et de mémoires contemporains, elle évoque les cérémonies et les réceptions officielles, mais aussi les soirées à la Cour et les séjours à Compiègne (les fameuses «séries»), Fontainebleau et Biarritz, bref le «métier de courtisan». Françoise BERCÉ (Mérimée, les beaux-arts et la Grande-Bretagne, pp. 37-55) rappelle les treize voyages, entre 1851 et 1868, et les articles rédigés après la visite de Crystal Palace, l'exposition de Manchester ou l'Exposition universelle de 1862. Mérimée se préoccupe de problèmes techniques (fixation et conservation des couleurs), pédagogiques (réforme de l'enseignement du dessin), des arts appliqués, mais aussi des grandes expositions de peinture (l'école anglaise, les préraphaélites). À propos des «Varia historiques et littéraires (1853-1870)», ces écrits apparemment disparates 
longtemps négligés, Antonia FONYI (pp. 56-68) remarque que la plupart témoignent des «préoccupations constantes et profondes» de l'écrivain. C'est l'archéologue que MarieLaure BERDEAUX-LE BRAZIDEC a choisi d'évoquer, sous un angle particulier (L'archéologue au service de l'empereur, pp. 69-97), Mérimée conseiller archéologique, par exemple pour le site gallo-romain de Champlieu, collaborateur pour l'Histoire de Jules César (1860-1866), ou expérimentateur intrépide du lancer de javelot avec l'amentum. Ce rôle de conseiller, Mérimée l'a poursuivi jusqu'en 1870. L'étude documentée évoque aussi un aspect rarement étudié: Mérimée, membre de la Commission des monuments historiques, constitua une collection fort hétéroclite dont la plupart des pièces furent données à des musées (on trouvera en annexe la liste des dons et legs faits par Mérimée aux musées français, entre 1847 et 1868). Signalons aussi l'intérêt de l'illustration: entre autres reproductions, le portait photographique de Mérimée vers 1868 (des archives de la duchesse Colonna), la frise de Gérôme sur laquelle Mérimée s'interroge dans son Salon de 1853, ou le cliché, attribué à Olympe Aguado, de la trirème en grandeur réelle mise à l'eau en 1861, tentative de reconstitution archéologique à laquelle collabora Mérimée. 